\title{
The utilization of the mesoporous Ti-SBA-15 catalyst in the epoxidation of allyl alcohol to glycidol and diglycidyl ether in the water medium
}

\author{
Agnieszka Wróblewska ${ }^{*}$, Edyta Makuch¹, Małgorzata Dzięcioł ${ }^{1}$, Roman Jędrzejewski², \\ Paweł Kochmański ${ }^{2}$, Agnieszka Kochmańska ${ }^{2}$, Lukasz Kucharski ${ }^{3}$ \\ ${ }^{1}$ West Pomeranian University of Technology, Szczecin, Institute of Organic Chemical Technology, Pułaskiego 10, \\ 70-322 Szczecin, Poland \\ ${ }^{2}$ West Pomeranian University of Technology, Szczecin, Faculty of Mechanical Engineering and Mechatronics, Institute of \\ Materials Science and Engineering, Piastów 19, 70-322 Szczecin, Poland \\ ${ }^{3}$ Pomeranian Medical University, Dermatopharmacotherapy Division, Department of Dermatology, Powstańców \\ Wielkopolskich 72, 70-111 Szczecin, Poland \\ "Corresponding author: e-mail: agnieszka.wroblewska@zut.edu.pl
}

\begin{abstract}
This work presents the studies on the optimization the process of allyl alcohol epoxidation over the Ti-SBA-15 catalyst. The optimization was carried out in an aqueous medium, wherein water was introduced into the reaction medium with an oxidizing agent (30 wt $\%$ aqueous solution of hydrogen peroxide) and it was formed in the reaction medium during the processes. The main investigated technological parameters were: the temperature, the molar ratio of allyl alcohol/hydrogen peroxide, the catalyst content and the reaction time. The main functions the process were: the selectivity of transformation to glycidol in relation to allyl alcohol consumed, the selectivity of transformation to diglycidyl ether in relation to allyl alcohol consumed, the conversion of allyl alcohol and the selectivity of transformation to organic compounds in relation to hydrogen peroxide consumed. The analysis of the layer drawings showed that in water solution it is best to conduct allyl alcohol epoxidation in direction of glycidol (selectivity of glycidol $54 \mathrm{~mol} \%$ ) at: the temperature of $10-17^{\circ} \mathrm{C}$, the molar ratio of reactants $0.5-1.9$, the catalyst content $2.9-4.0$ $\mathrm{wt} \%$, the reaction time $2.7-3.0 \mathrm{~h}$ and in direction of diglycidyl ether (selectivity of diglycidyl ether $16 \mathrm{~mol} \%$ ) at: the temperature of $18-33^{\circ} \mathrm{C}$, the molar ratio of reactants $0.9-1.65$, the catalyst content $2.0-3.4 \mathrm{wt} \%$, the reaction time 1.7-2.6 h. The presented method allows to obtain two very valuable intermediates for the organic industry.
\end{abstract}

Keywords: glycidol, diglycidyl ether, Ti-SBA-15 catalyst, allyl alcohol epoxidation, hydrogen peroxide.

\section{INTRODUCTION}

The processes of allylic compounds epoxidation over titanium silicalite catalysts are very popular among researchers ${ }^{1-2}$. This is due to the fact that in the presence of titanium silicalite catalysts, these processes can be conducted in mild conditions (at a low temperature and at an atmospheric pressure) and using a cheap and easily accessible oxidizing agent - hydrogen peroxide. Moreover, another benefit associated with the use of hydrogen peroxide as an oxidizer is that the only product of this compound conversion is water. Until now, processes of allylic compounds epoxidation were performed over the following titanium silicalite catalysts: TS-1, TS-2, Ti-Beta, Ti-MWW, Ti-MCM-41 and Ti-MCM-48 ${ }^{3-9}$. The epoxidation process over these catalysts was mainly conducted in methanol as a solvent. Water was not considered as an attractive medium for the epoxidation processes due to hydrolysis of the epoxide ring, which reduced selectivity of transformation into the epoxy compound and resulted in the formation of diol (for allyl alcohol it was glycerol) which is of much less practical importance. Furthermore, when it comes to mesoporous titanium silicalite catalysts (Ti-MCM-41 and Ti-MCM-48), the structure of these catalysts was disintegrated in the aqueous medium and at elevated temperature. Thus, researchers started looking for new titanium silicalite catalysts that would be stable (taking into account both the disintegration of the structure and the titanium leaching). This resulted in the discovery of the Ti-MWW and the Ti-SBA- 15 materials. The latter material is a mesoporous catalyst with pore walls of greater thickness than Ti-MCM-41. What is more, the main channels in the structure of this catalyst are connected to each other with additional ones, which reinforce the whole structure ${ }^{10-13}$. Taking into consideration the structure of the catalyst, it can be very active in epoxidation processes that are conducted in aqueous medium. Moreover, a large advantage associated with its use may be the fact that there will be a possibility to use it in this process longer when compared to older titanium silicalite catalysts. Our studies also show that the mesoporous material Ti-SBA-15 is much more stable, taking into account the leaching of titanium from its structure in the process of epoxidation. This is a great advantage considering the need to recover it from the reaction mixture and periodical regeneration.

The earlier studies on the epoxidation of allyl alcohol over TS-1, TS-2, Ti-Beta, Ti-MWW, Ti-MCM-41 and Ti-MCM-48 catalysts showed that diglycidyl ether was not present in the post-reaction mixtures, independent on used catalyst and solvent (methanol, acetonitrile or water). Our studies show that this compound is one of the main by-products in this process in the presence of water as a solvent when the epoxidation is performed over newest titanium silicalite catalyst Ti-SBA-15. Establishing the most beneficial conditions of glycidol and diglycidyl ether obtaining is very important problem because these compounds have a lot of applications in organic industry. Glycidol is used for the production of surface active agents which are included in the composition of: cosmetic formulation for moistening and cleaning of skin, shampoo and toothpaste. Other groups of glycidol applications include dispersive agents, plasticizers for resins and rubber and the detergents in petroleum industry ${ }^{14-18}$. Diglycidyl ether has utilization: in production of linear, branched and cyclic oligoglycerols 
used in the production of surfactants ${ }^{\mathbf{1 9}}$, in preparation of anti-arrhythmia agents ${ }^{\mathbf{2 0}}$, in production of component of other pharmaceuticals and medicines, for example cryptands $^{\mathbf{2 1 - 2 2}}$, in preparation of lubricating oil additives ${ }^{\mathbf{2 3}}$, in the synthesis of aminoethers ${ }^{24}$.

The aim of this work was the establishing of the most beneficial conditions for carrying out the process of allyl alcohol epoxidation over the Ti-SBA-15 catalyst and in aqueous medium, but water was only introduced into reaction medium with $30 \mathrm{wt} \%$ hydrogen peroxide or it was formed during the process. The established the most beneficial conditions should allow to obtain the most useful products of this process (glycidol and diglycidyl ether) with the highest selectivities.

\section{EXPERIMENTAL}

Catalyst Ti-SBA-15 was obtained by the method described in the literature ${ }^{\mathbf{1 3}}$. The full description of the catalyst was presented in our previous work?

In the epoxidation of allyl alcohol the following raw materials were used: allyl alcohol (98\%, Fluka) and hydrogen peroxide (30 wt \% water solution, POCH Gliwice). The process was carried out in a glass vial with the capacity of $12 \mathrm{~cm}^{3}$ equipped with a rubber septum and a capillary. The vials were located in a shaker holder and immersed in a water bath.

In order to calculate the mass balance, the postreaction mixtures were analyzed in the following way: unreacted hydrogen peroxide was determined by means of iodometric method ${ }^{25}$, glycerol formed in the process was determined by means of potentiometric method ${ }^{\mathbf{2 6}}$. The remaining products and the unreacted organic substrate were analyzed by means of gas chromatography. The chromatographic analyses were performed on the FOCUS apparatus with a flame-ionization detector (FID) fitted with Quadrex capillary columns filled with methylphenyl-siloxanes. The parameters of chromatographic separation were as follows: the pressure of helium $50 \mathrm{kPa}$, sensitivity 10 , the temperature of the sample chamber $150^{\circ} \mathrm{C}$, the detector temperature $250^{\circ} \mathrm{C}$, the temperature of the thermostat was increasing according to the following program: isothermally at $40^{\circ} \mathrm{C}$ for 3 minutes, an increase to $250^{\circ} \mathrm{C}$ at the rate of $10^{\circ} \mathrm{C} / \mathrm{min}$, isothermally at $250^{\circ} \mathrm{C}$ for 5 minutes, cooling to $60^{\circ} \mathrm{C}$.

\section{RESULTS AND DISCUSSION}

During the process of allyl alcohol epoxidation as a main product glycidol is formed. But this epoxide compound undergoes very easy a hydration in reaction conditions. These transformations can be described as follows:

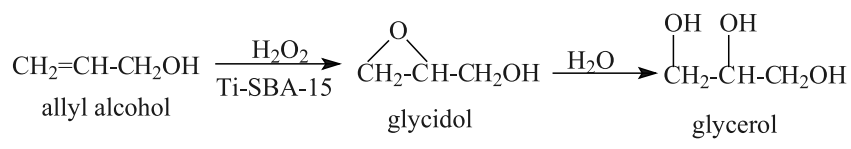

One of the main by-products of this process is diglycidyl ether. Taking into account the results obtained in this work and in our previous works ${ }^{3,9}$, the possible three ways of diglycidyl ether forming can be presented:
1)

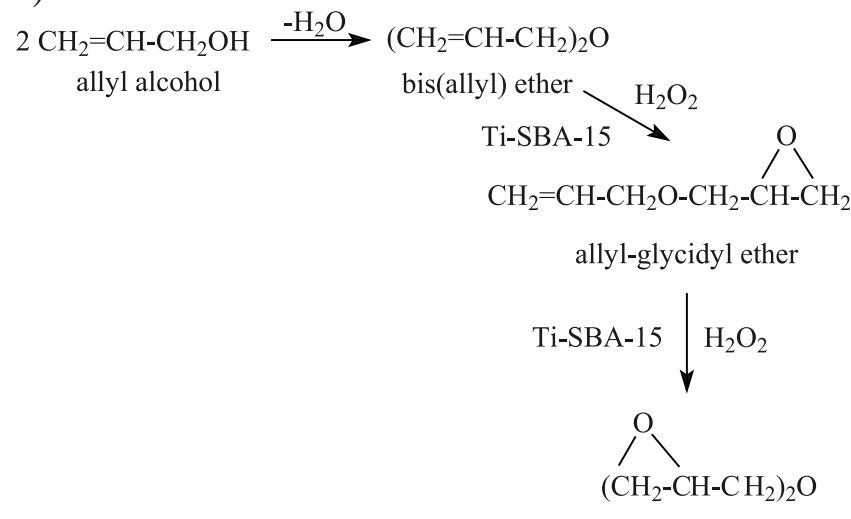

diglycidyl ether

2)

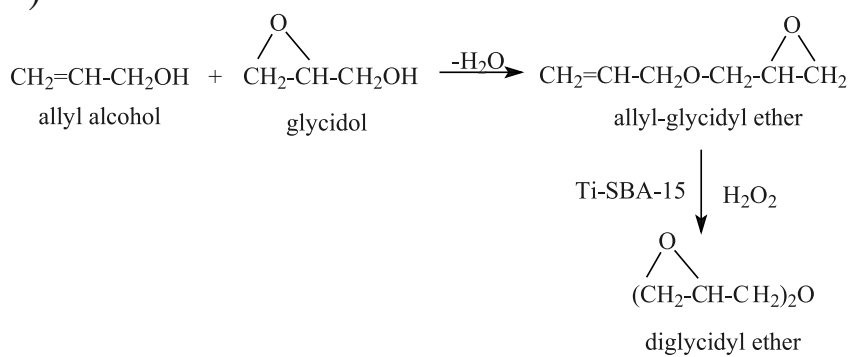

3)

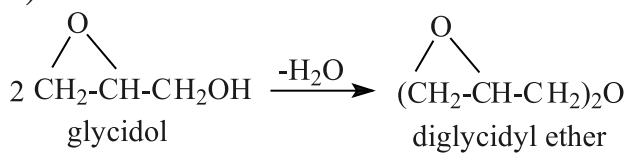

During the process also the decomposition of ethers undergoes, especially diglycidyl ether. The decomposition of this compound is probably also connected with hydration of epoxide rings and formation of glycerol. The reactions of diglycidyl ether decomposition and in the next step hydration are presented below:

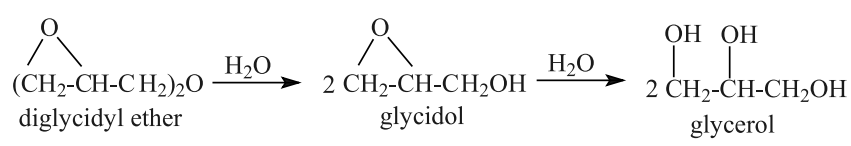

The reactions presented above show that the studied process is very complicated and for it description very complex method should be used, for example mathematical optimization.

The optimization of the technological parameters of allyl alcohol epoxidation (AA) in the presence of water and over Ti-SBA-15 catalyst was conducted using a rotatable-uniform design ${ }^{27-30}$. Experiments were planed and calculations were made using computer software Cadex: Esdet 2.2. ${ }^{31}$. The design was carried out for four input values $\mathrm{x}_{1}-\mathrm{x}_{4}$ (process parameters): $\mathrm{x}_{1}$ - temperature $10-40^{\circ} \mathrm{C}, \mathrm{x}_{2}-$ molar ratio of $\mathrm{AA} / \mathrm{H}_{2} \mathrm{O}_{2}$ $0.5-2.0, \mathrm{x}_{3}$ - content of catalyst Ti-SBA-15 2.0-4.0 wt $\%$ and $\mathrm{x}_{4}-$ reaction time of $1-3 \mathrm{~h}$.

The total number of experiments was 31 . The real values of the input values $\mathrm{x}_{1}-\mathrm{x}_{4}$ were converted into the coded values (non-dimensional). Thanks to the normalization process, a universal design with values of the input values normalized in a non-dimensional interval $[-2,2]$ was obtained. Table 1 shows the input values and 
Table 1. The levels of the examined variables for the process of AA epoxidation in the presence of water

\begin{tabular}{|l|c|c|c|c|c|}
\hline Level & $\begin{array}{c}\text { Coded } \\
\text { variables }\end{array}$ & $\begin{array}{c}\text { Temperature } \\
{\left[{ }^{\circ} \mathrm{C}\right]}\end{array}$ & $\begin{array}{c}\text { Molar ratio } \\
\mathrm{AA} / \mathrm{H}_{2} \mathrm{O}_{2}\end{array}$ & $\begin{array}{c}\text { Ti-SBA-15 } \\
\text { content } \\
{[\text { wt } \%]}\end{array}$ & $\begin{array}{c}\text { Reaction time } \\
{[\mathrm{h}]}\end{array}$ \\
\hline & $\mathrm{X}_{\mathrm{i}}$ & $\mathrm{X}_{1}$ & $\mathrm{X}_{2}$ & $\mathrm{X}_{3}$ & $\mathrm{X}_{4}$ \\
\hline Basic & 0 & 25 & 1.3 & 3.0 & 2 \\
\hline Higher & 1 & 33 & 1.6 & 3.5 & 2.5 \\
\hline Lower & -1 & 18 & 0.9 & 2.5 & \\
\hline Star higher & 2 & 40 & 2.0 & 4.0 & 3 \\
\hline Star lower & -2 & 10 & 0.5 & 2.0 & 1 \\
\hline
\end{tabular}

the normalized input values at levels resulting from the rotatable-uniform design.

The following functions were accepted as response functions: $z_{1}-$ selectivity of transformation to glycidol in relation to AA consumed $\left(\mathrm{S}_{\mathrm{gly} / \mathrm{AA}}\right), \mathrm{z}_{2}$ - selectivity of transformation to diglycidyl ether in relation to AA consumed $\left(\mathrm{S}_{\mathrm{DGE} / \mathrm{AA}}\right)$, the conversion of $\mathrm{AA}\left(\mathrm{C}_{\mathrm{AA}}\right)$ and the selectivity of transformation to organic compounds in relation to hydrogen peroxide consumed $\left(\mathrm{S}_{\text {org. com. } / \mathrm{H}_{2} \mathrm{O}_{2}}\right)$.

Table 2 shows a design matrix in a form of normalized values and the real values of response functions $z_{1}-z_{4}$ obtained experimentally.

The influence of normalized independent factors $\left(\mathrm{X}_{1}: \mathrm{X}_{4}\right)$ in the process of allyl alcohol epoxidation on the value of the response function is presented with the second-degree algebraic polynomial:

$\mathrm{Z}=\mathrm{Z}\left(\mathrm{X}_{\mathrm{k}}\right)=\mathrm{b}_{0}+\mathrm{b}_{1} * \mathrm{X}_{1}+\ldots+\mathrm{b}_{\mathrm{i}}{ }^{*} \mathrm{X}_{\mathrm{i}}+\mathrm{b}_{11} * \mathrm{X}_{1}{ }^{2}$ $+\ldots+b_{i i} * X_{i}^{2}+b_{12} * X_{1} X_{2}+\ldots+b_{i-1, i} * X_{i-1} * X_{i}$

for $X_{k} \in[-2,2]$, where: $b_{i}$ - normalized coefficient of the approximation function;

$\mathrm{N}_{\mathrm{b}}$ - the number of polynomial coefficients; $\mathrm{N}_{\mathrm{b}}=0,5$ * $(i+1) *(i+2), i-$ the number of the input variables $\mathrm{X}_{\mathrm{k}} ; \mathrm{k}=1,2, \ldots, \mathrm{i}$
To obtain response functions containing the real factors of an approximating function and the real input variables $\mathrm{x}_{\mathrm{k}}$ (technological parameters), normalized values of input variables $X_{k}$ were converted into real using the following formulas: $\mathrm{X}_{1}=0.13 *\left(\mathrm{x}_{1}-10\right)-2, \mathrm{X}_{2}=2.67 *\left(\mathrm{x}_{2}-0.5\right)-2, \mathrm{X}_{3}$ $=2^{*}\left(\mathrm{x}_{3}-2\right)-2, \mathrm{X}_{4}=2^{*}\left(\mathrm{x}_{4}-1\right)-2$.

The factors of regression equations for normalized input variables were determined over the least squares method, using the matrix analysis (Table 3). After determining the function that approximated the results of measurements, the adequacy of the obtained function was verified based on the Fisher-Snedecor test by comparing them with the critical value of $F(0.05)$ read from the tables ${ }^{32}$. Moreover, relative errors of approximation and multidimensional correlation coefficients $(\mathrm{R})$ were calculated for each function. Table 3 shows the values of factor $\mathrm{R}$ and $\Delta \mathrm{z}_{\max }$ - the maximum error of approximation. In Table 3 are also given the values of : $\mathrm{S}_{\text {repeat }}$ - variance of inaccuracy, $\mathrm{f}_{\text {repeat }}$ - freedom degrees number of variance of inaccuracy, $\mathrm{S}^{2}$ adeq - variance of adequacy and $\mathrm{f}_{\text {adeq }}$ - freedom degrees number of variance of adequacy.

The maxima of the obtained regression equations were determined mathematically using computer software $\mathrm{Ca}$ dex Esdet $2.2^{33}$. The calculations included the methods

Table 2. Design matrix and experimental results (for the response functions z1-z2)

\begin{tabular}{|c|c|c|c|c|c|c|c|c|}
\hline & $\mathrm{X}_{1}$ & $x_{0}$ & $\mathrm{X}_{3}$ & $X_{4}$ & $S_{\text {gly/AA }}$ & $S_{\text {DGEIAA }}$ & $\mathrm{C}_{\mathrm{AA}}$ & $\mathrm{S}_{\text {org. com. } / \mathrm{H}_{2} \mathrm{O}_{2}}$ \\
\hline & $\lambda_{1} 1$ & $\lambda_{2}$ & $\lambda_{3}$ & $\lambda_{4}$ & \multicolumn{4}{|c|}{$[\mathrm{mol} \%]$} \\
\hline 1 & 1 & -1 & -1 & -1 & 10 & 0 & 60 & 53 \\
\hline 2 & 1 & -1 & -1 & -1 & 20 & 0 & 55 & 51 \\
\hline 3 & -1 & 1 & -1 & -1 & 15 & 0 & 28 & 46 \\
\hline 4 & 1 & -1 & -1 & 1 & 22 & 0 & 31 & 55 \\
\hline 5 & 1 & 1 & -1 & -1 & 9 & 0 & 59 & 55 \\
\hline 6 & 1 & -1 & 1 & -1 & 11 & 0 & 56 & 54 \\
\hline 7 & -1 & 1 & 1 & -1 & 10 & 0 & 37 & 51 \\
\hline 8 & 1 & 1 & 1 & -1 & 17 & 0 & 31 & 51 \\
\hline 9 & -1 & -1 & -1 & 1 & 15 & 11 & 71 & 68 \\
\hline 10 & 1 & -1 & -1 & 1 & 9 & 0 & 53 & 48 \\
\hline 11 & -1 & 1 & -1 & 1 & 20 & 0 & 39 & 58 \\
\hline 12 & 1 & 1 & -1 & -1 & 11 & 0 & 32 & 49 \\
\hline 13 & -1 & -1 & 1 & 1 & 18 & 0 & 53 & 58 \\
\hline 14 & 1 & -1 & 1 & 1 & 8 & 0 & 52 & 48 \\
\hline 15 & -1 & 1 & 1 & 1 & 24 & 0 & 36 & 50 \\
\hline 16 & 1 & 1 & 1 & 1 & 13 & 0 & 25 & 42 \\
\hline 17 & -2 & 0 & 0 & 0 & 22 & 0 & 40 & 58 \\
\hline 18 & 2 & 0 & 0 & 0 & 9 & 18 & 38 & 49 \\
\hline 19 & 0 & -2 & 0 & 0 & 17 & 0 & 96 & 52 \\
\hline 20 & 0 & 2 & 0 & 0 & 18 & 19 & 30 & 61 \\
\hline 21 & 0 & 0 & -2 & 0 & 15 & 0 & 44 & 51 \\
\hline 22 & 0 & 0 & 2 & 0 & 10 & 15 & 47 & 58 \\
\hline 23 & 0 & 0 & 0 & -2 & 12 & 0 & 37 & 49 \\
\hline 24 & 0 & 0 & 0 & 2 & 10 & 15 & 45 & 59 \\
\hline 25 & 0 & 0 & 0 & 0 & 9 & 15 & 44 & 59 \\
\hline 26 & 0 & 0 & 0 & 0 & 9 & 17 & 40 & 57 \\
\hline 27 & 0 & 0 & 0 & 0 & 8 & 16 & 44 & 58 \\
\hline 28 & 0 & 0 & 0 & 0 & 9 & 17 & 44 & 59 \\
\hline 29 & 0 & 0 & 0 & 0 & 8 & 16 & 44 & 58 \\
\hline 30 & 0 & 0 & 0 & 0 & 8 & 16 & 41 & 60 \\
\hline 31 & 0 & 0 & 0 & 0 & 8 & 16 & 41 & 60 \\
\hline
\end{tabular}


Table 3. Coefficients of the regression equations Z1-Z2 and results of statistical analyses

\begin{tabular}{|c|c|c|c|c|}
\hline & $Z_{1}$ & $\mathrm{Z}_{2}$ & $Z_{3}$ & $\mathrm{Z}_{4}$ \\
\hline$b_{00}$ & $8.43^{*}$ & 16.14 & $42.57^{*}$ & $58,710^{*}$ \\
\hline$b_{01}$ & $-1.46^{*}$ & $1.00^{*}$ & $-2.17^{*}$ & $-2,380^{*}$ \\
\hline$b_{02}$ & $1.38^{*}$ & $1.08^{*}$ & -13.83 & $-0,630^{*}$ \\
\hline$b_{03}$ & $-0.88^{*}$ & $0.75^{*}$ & -0.58 & $-0,290$ \\
\hline $\mathrm{b}_{04}$ & 0.04 & $1.75^{\star}$ & 0.83 & $1,040^{*}$ \\
\hline$b_{11}$ & $1.84^{*}$ & $-3.06^{*}$ & $-1.26^{*}$ & $-1,610^{*}$ \\
\hline$b_{12}$ & -0.19 & $0.75^{\star}$ & 0.38 & $1,560^{*}$ \\
\hline$b_{13}$ & $-0.81^{*}$ & $0.75^{\star}$ & 0.38 & 0,190 \\
\hline$b_{14}$ & $-3.81^{*}$ & $-0.75^{\star}$ & $-1.63^{*}$ & $-3,310^{*}$ \\
\hline$b_{22}$ & $2.34^{*}$ & $-2.93^{*}$ & $4.73^{*}$ & $-0,980^{*}$ \\
\hline$b_{23}$ & -0.19 & $0.75^{*}$ & $1.13^{*}$ & $-0,560$ \\
\hline$b_{24}$ & 0.19 & $-0.75^{\star}$ & 0.38 & $-0,810^{*}$ \\
\hline$b_{33}$ & $1.09^{*}$ & $-3.43^{*}$ & 0.36 & $-1,360^{*}$ \\
\hline$b_{34}$ & $0.81^{*}$ & $-0.75^{\star}$ & $-2.38^{*}$ & $-1,940^{*}$ \\
\hline$b_{44}$ & $0.71^{*}$ & $-3.43^{*}$ & -0.77 & $-1,610^{*}$ \\
\hline$S_{\text {repeat }}^{2}$ & 0.29 & 0.48 & 3.29 & 1,24 \\
\hline$F_{\text {repeat }}$ & 6.00 & 6.00 & 6.00 & 6,00 \\
\hline $\mathrm{S}_{\text {adeq }}^{2}$ & 4.82 & 54.63 & 18.64 & 16,35 \\
\hline$F_{\text {adeg }}$ & 15.00 & 15,00 & 15.00 & 15,00 \\
\hline $\mathrm{R}$ & 0.95 & 0.76 & 0.97 & 0,85 \\
\hline$\Delta z_{\max }$ & 3.88 & 12.42 & 6.83 & 7,46 \\
\hline
\end{tabular}

*essentials coefficients

by Hooke-Jeeves and Gauss-Seidel. The maximum values of independent variables for a given regression function marked using these methods were identical. Table 4 shows maximum values of response functions $z_{1}-z_{2}$ and the corresponding real values of independent variables.

\section{The selectivity of transformation to glycidol in relation to AA consumed $\left(\mathrm{z}_{1}\right)$}

The influence of changes of two selected parameters on the selectivity of transformation to glycidol in relation to AA consumed $\left(z_{1}\right)$ at optimal values of the remaining parameters that allow obtaining the maximum value of the tested function is shown in Figures 1-3 (contour drawings).

Table 4 shows that the optimal parameters that allow achieving the highest value of the selectivity of glycidol (54 mol\%) are as follows: temperature of $11^{\circ} \mathrm{C}$, molar ratio of reactants of 1.8, catalyst content of $3.9 \mathrm{wt} \%$ and reaction time of $2.9 \mathrm{~h}$. A detailed analysis of Figure 1 shows that for the temperatures in the range of $10-23^{\circ} \mathrm{C}$, it is the best to operate within the range of molar ratios of reactants ranging from about 0.5 to 1.9 . At these low temperatures and within this range of molar ratios of reactants the glycidol molecules are probably more stable in reaction medium and resistant to the reaction with water molecules. Additionally, for the molar ratios of $\mathrm{AA} / \mathrm{H}_{2} \mathrm{O}_{2}$ above 1.0 to 1.9 , the excess of $\mathrm{AA}$ molecules causes that the molecules of glycidol can be surrounded by AA molecules and probably because of this phenomenon the epoxide rings are not opened so fast. On the other hand, the increasing of temperature causes that the tendency of the opening of the epoxide ring raises and at the temperatures above about $25^{\circ} \mathrm{C}$, the selectivity of glycidol decreases practically independent

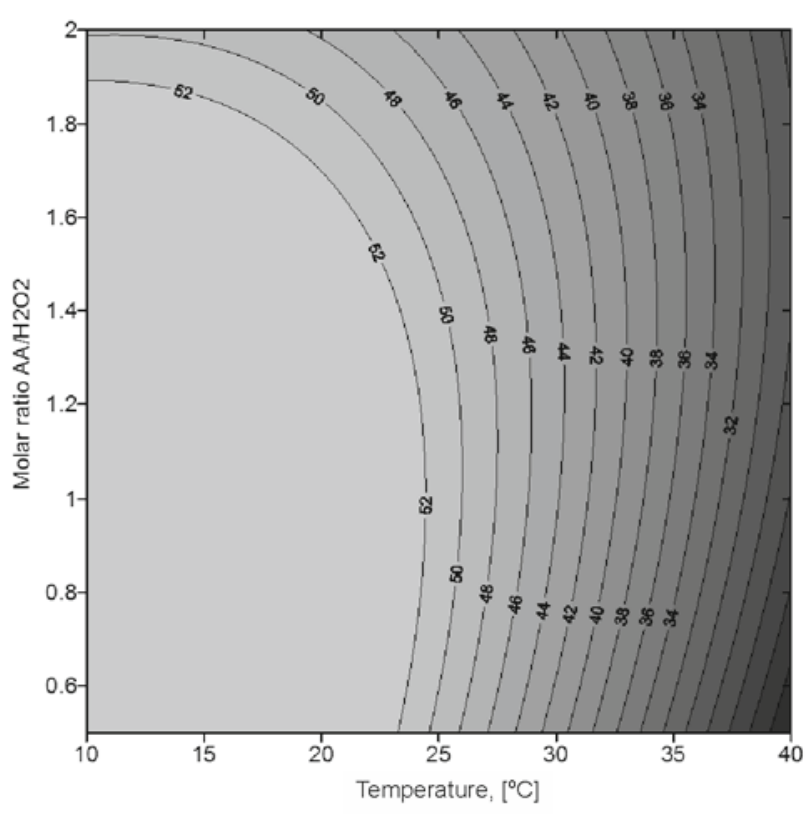

Figure 1. The influence of the technological parameters on the selectivity of transformation to glycidol in relation to AA consumed - the dependence of temperature and molar ratio of $\mathrm{AA} / \mathrm{hydrogen}$ peroxide (the content of Ti-SBA-15 $3.9 \mathrm{wt} \%$, reaction time $2.9 \mathrm{~h}$ )

on the molar ratio of AA/hydrogen peroxide. It shows that at higher temperatures, the utilization of the molar ratios of AA/hydrogen peroxide above 1 has probably a slighter influence on the stability of glycidol molecules and thus water molecules have easy access to epoxide ring of glycidol. As a result of this situation glycerol is formed in higher amount in post-reaction mixtures.

Table 4. Parameters determining maximum values of the response functions

\begin{tabular}{|l|c|c|c|c|c|}
\hline Functions & & $\mathrm{S}_{\text {gly/AA }}$ & $\mathrm{S}_{\mathrm{DGE} / \mathrm{AA}}$ & $\mathrm{C}_{\mathrm{AA}}$ & $\mathrm{S}_{\text {org. com./H }} \mathrm{O}_{2}$ \\
\hline $\begin{array}{l}\text { Maximum values of the response } \\
\text { function }\end{array}$ & {$[\mathrm{mol} \%]$} & 54 & 16 & 100 & 73 \\
\hline Temperature & {$\left[{ }^{\circ} \mathrm{C}\right]$} & 11 & 28 & 19 & 11 \\
\hline Molar ratio AA/ $\mathrm{H}_{2} \mathrm{O}_{2}$ & & 1.8 & 1.4 & 0.5 & 0.7 \\
\hline Ti-SBA-15 content & {$[\mathrm{wt} \%]$} & 3.9 & 3.1 & 2.0 & 2.3 \\
\hline Reaction time & {$[\mathrm{h}]$} & 2.9 & 2.0 & 2.9 & 3.0 \\
\hline
\end{tabular}


Figure 2 shows that at the temperature range of $10-17^{\circ} \mathrm{C}$, when conducting the process with a content of catalyst Ti-SBA-15 from 2.9-4.0 wt\%, we should always get the selectivity of glycidol of about $54 \mathrm{~mol} \%$. The rising of temperature to $40^{\circ} \mathrm{C}$ decreases the selectivity of glycidol to about $25 \mathrm{~mol} \%$, practically independent on the content of the Ti-SBA- 15 catalyst. The performing the process of AA epoxidation at the temperature of $20^{\circ} \mathrm{C}$ allows to achieve a little lower value of the selectivity of glycidol - about $47 \mathrm{~mol} \%$.

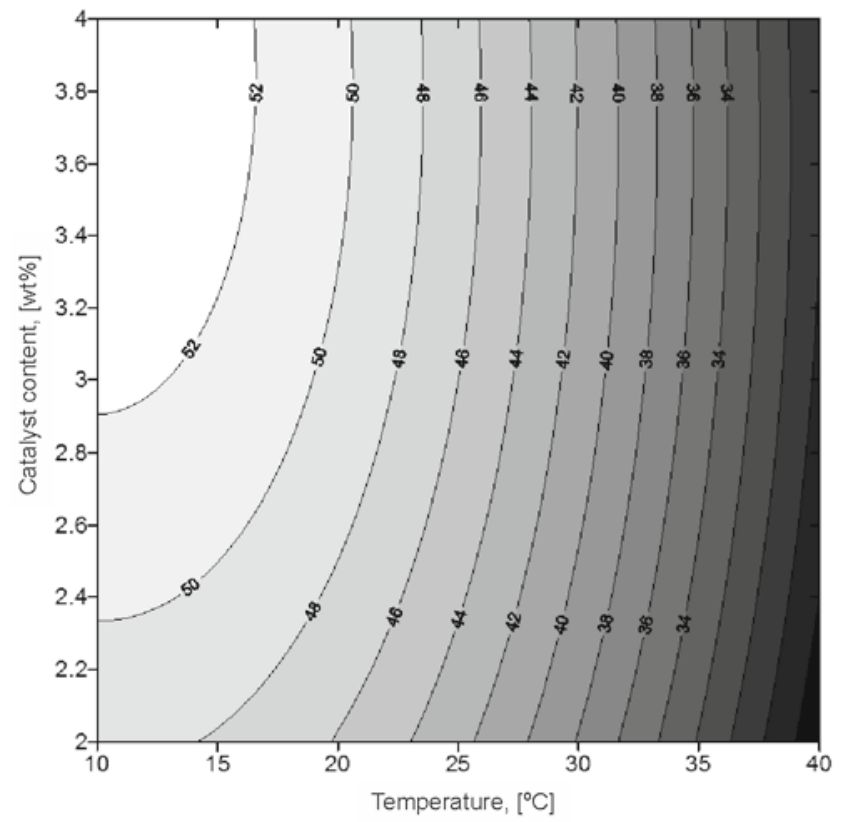

Figure 2. The influence of the technological parameters on the selectivity of transformation to glycidol in relation to AA consumed - the dependence of temperature and the content of Ti-SBA-15 (the molar ratio AA/hydrogen peroxide 1.8 , reaction time $2.9 \mathrm{~h}$ )

Figure 3 shows that at the temperatures from $10^{\circ} \mathrm{C}$ to about $18^{\circ} \mathrm{C}$, when we conduct the process at the reaction time 2.7 up to $3.0 \mathrm{~h}$, we can obtain the highest value of selectivity of glycidol $-54 \mathrm{~mol} \%$. The raising of the temperature from $18^{\circ} \mathrm{C}$ to $25^{\circ} \mathrm{C}$ for the reaction time above $2 \mathrm{~h}$ causes slight changes in values of the selectivity of glycidol (from $54 \mathrm{~mol} \%$ to $44-46 \mathrm{~mol} \%$ ). The performing the process at the temperatures of $10-25^{\circ} \mathrm{C}$ for the reaction time $1-2 \mathrm{~h}$ allows to obtain the selectivity of glycidol from $16 \mathrm{~mol} \%$ to $46 \mathrm{~mol} \%$. For the temperatures from $25^{\circ} \mathrm{C}$ to $40^{\circ} \mathrm{C}$ and the reaction time to $2 \mathrm{~h}$ the changes in values of the selectivity of glicydol are lower (from 34 to $46 \mathrm{~mol} \%$ ). For the higher temperatures $\left(25^{\circ} \mathrm{C}\right.$ to $\left.40^{\circ} \mathrm{C}\right)$ and for longer reaction time (from $2 \mathrm{~h}$ to $3 \mathrm{~h}$ ) the changes of the selectivity of glycidol are similar. Generally, the lower temperatures and the reaction time above $2 \mathrm{~h}$ is the most beneficial to perform the process of epoxidation, because at lower temperatures the hydration of epoxide ring proceeds slower.

\section{The selectivity of transformation to diglycidyl ether in relation to AA consumed $\left(z_{2}\right)$}

The influence of changes of two chosen parameters on the selectivity of diglycidyl ether $\left(\mathrm{z}_{2}\right)$ at optimal values of the remaining parameters that allow obtaining the

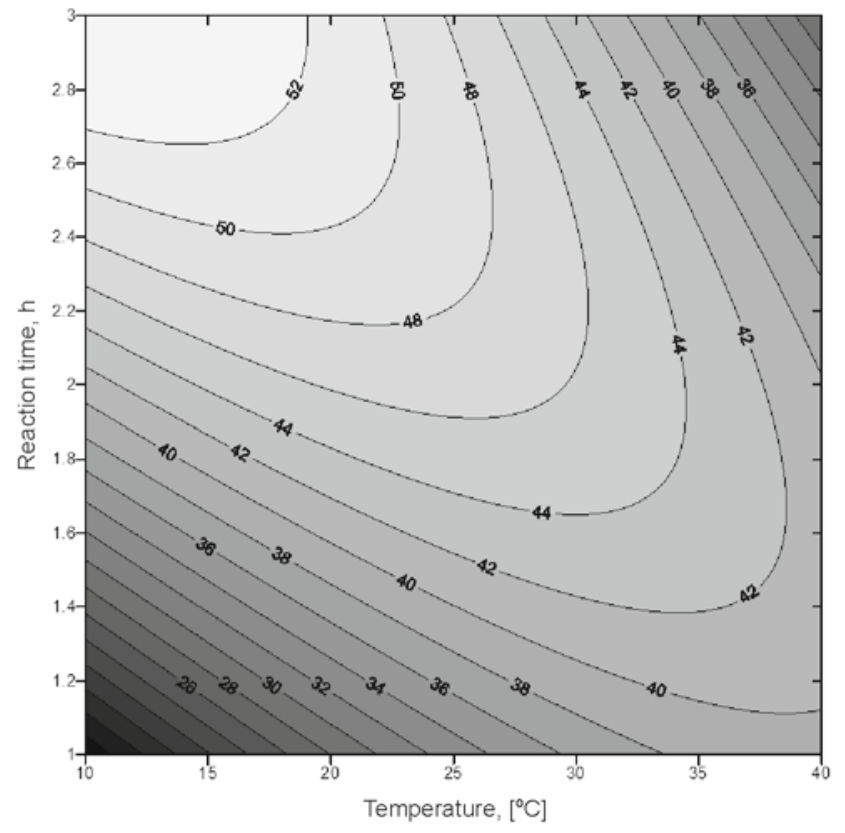

Figure 3. The influence of the technological parameters on the selectivity of transformation to glycidol in relation to AA consumed - the dependence of temperature and reaction time (the molar ratio $\mathrm{AA} /$ hydrogen peroxide 1.8, the content of Ti-SBA-15 $3.9 \mathrm{wt} \%$ )

maximum value of the tested function is presented in Figures 4-6.

Table 4 shows that the most favorable conditions for the epoxidation of allyl alcohol in the direction of diglycidyl ether were as follows (maximum selectivity of diglycidyl ether is $16 \mathrm{~mol} \%$ ): the temperature of $28^{\circ} \mathrm{C}$, the molar ratio of reactants of 1.4 , the content of the catalyst of 3.1 and reaction time of $2 \mathrm{~h}$. Figure 4 shows that the epoxidation of $\mathrm{AA}$ at temperatures ranging from 18 up to $33^{\circ} \mathrm{C}$, and molar ratios of reactants from 0.9 up to 1.65 , also allows obtaining optimal values of

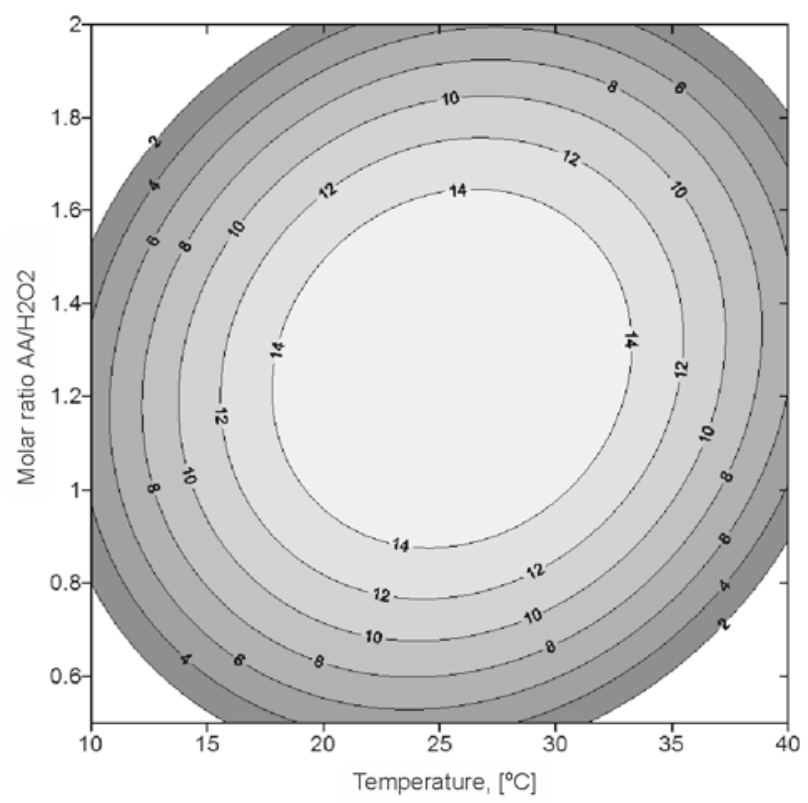

Figure 4. The influence of the technological parameters on the selectivity of transformation to diglycidyl ether in relation to AA consumed - the dependence of temperature and molar ratio of $\mathrm{AA} /$ hydrogen peroxide (the content of Ti-SBA-15 $3.1 \mathrm{wt} \%$, reaction time $2.0 \mathrm{~h}$ ) 
the function of the process $(16 \mathrm{~mol} \%)$. At temperatures below $10^{\circ} \mathrm{C}$ for the whole range of the investigated molar ratios of reactants the processes of the etherification is inhibited, whereas at temperatures above $33^{\circ} \mathrm{C}$, probably the decomposition of diglycidyl ether and hydration of the epoxide rings occurs, what reduces the amount of diglycidyl ether formed in the process.

Figure 5 shows that the highest selectivity of diglycidyl ether $(16 \mathrm{~mol} \%)$ can be obtained at temperatures of $14-39^{\circ} \mathrm{C}$ and at the catalyst content ranging from 2.0 up to 3.4 wt. $\%$. At lower temperatures $\left(10-14^{\circ} \mathrm{C}\right)$ and for the catalyst content above $3.4 \mathrm{wt} \%$ the etherification process is inhibited. Moreover, at temperatures above $35^{\circ} \mathrm{C}$ and for catalyst content $3.5 \mathrm{wt} \%$ also diglycidyl ether is also not formed, but in this case probably the decomposition of the diglycidyl ether took place and this product is not detected in the post-reaction mixtures.

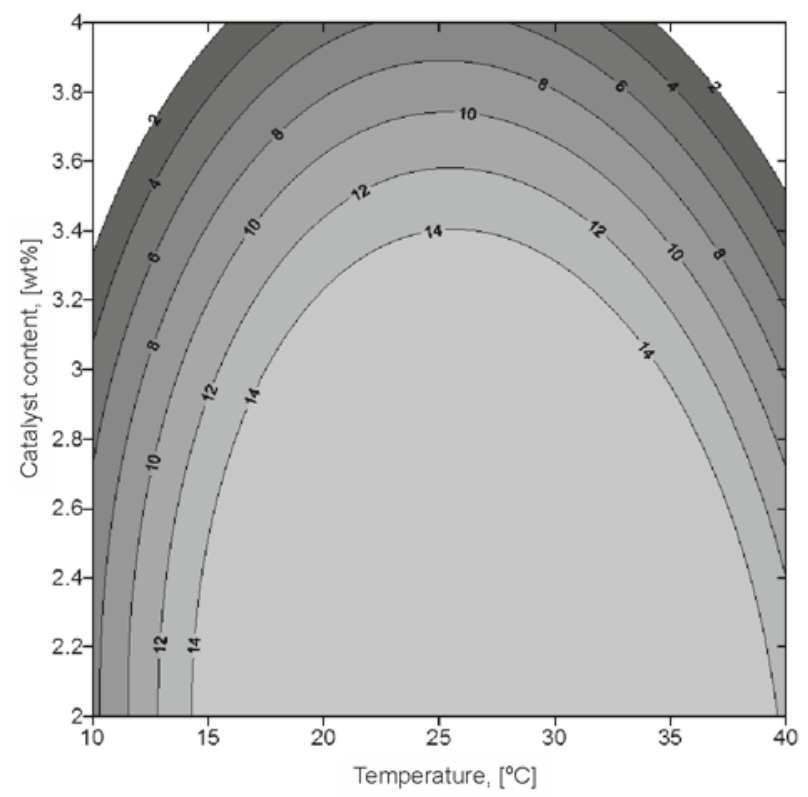

Figure 5. The influence of the technological parameters on the selectivity of transformation to diglycidyl ether in relation to AA consumed - the dependence of temperature and the content of Ti-SBA-15 (the molar ratio AA/ hydrogen peroxide 1.4 , reaction time $2.0 \mathrm{~h}$ )

Figure 6 shows that at temperatures ranging from $18-34^{\circ} \mathrm{C}$ it is best to carry out the process at time intervals from 1.7 up to $2.65 \mathrm{~h}$. For the reaction time to about $1.15 \mathrm{~h}$ independent on the temperature of the process performing the etherification process takes no place or the decomposition the diglycidyl ether molecules (for higher temperatures) can perform, thus the diglycidyl ether is not present in the post-reaction mixtures. The same phenomenon is observed for low temperatures $\left(10-11^{\circ} \mathrm{C}\right)$ independent on the used reaction time. For higher temperatures and for short reaction time (to $1.4 \mathrm{~h}$ ) diglycidyl ether is also not present in the post-reaction mixtures. It is possible that these reaction times are not enough to formation this product or the decomposition of this product proceeds. On the other hand, for highest temperatures and for longest time $(2.65-3 \mathrm{~h})$ this compound is also not detected. It is possible that at these conditions the molecule of diglycidyl ether is not stable and in the consequence of its breakdown glycidol and glycerol molecules are formed.

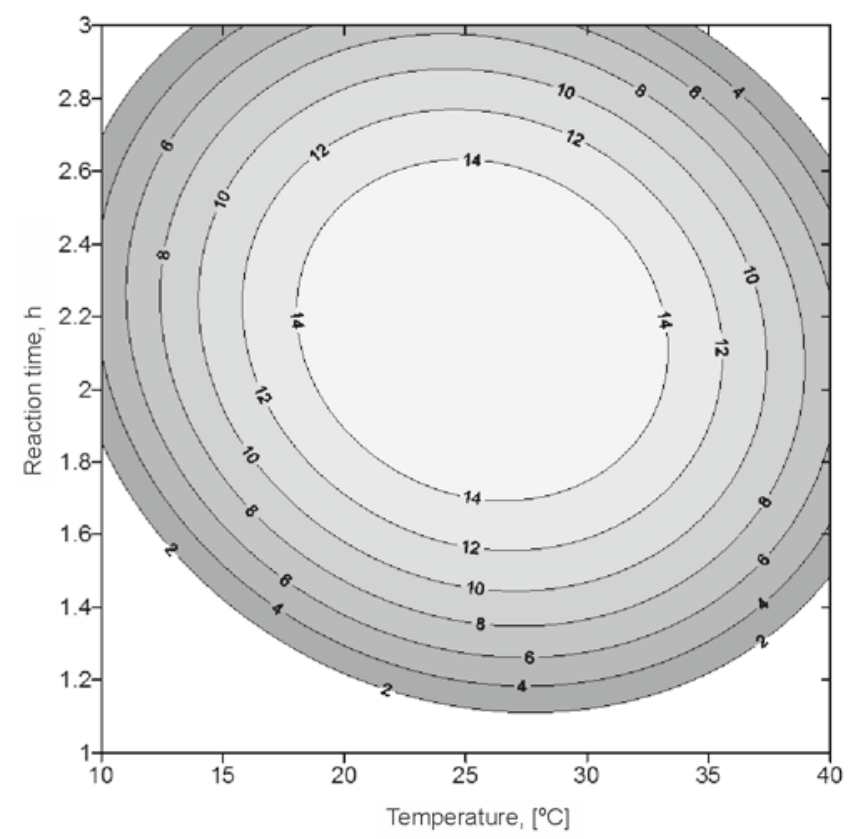

Figure 6. The influence of the technological parameters on the selectivity of transformation to diglycidyl ether in relation to AA consumed - the dependence of temperature and reaction time (the molar ratio $\mathrm{AA} /$ hydrogen peroxide 1.4 , the content of Ti-SBA-15 3.1 wt $\%$ )

The conversion of $\mathrm{AA}\left(\mathrm{z}_{3}\right)$

The influence of changes of two chosen parameters on the conversion of $\mathrm{AA}\left(\mathrm{z}_{3}\right)$ at optimal values of the remaining parameters that allow obtaining the maximum value of the tested function is presented in Figures 7-9.

Table 4 shows that the most favorable conditions for obtaining of $100 \mathrm{~mol} \%$ conversion of AA were as follows: the temperature of $19^{\circ} \mathrm{C}$, the molar ratio of reactants of 0.5 , the content of the catalyst of 2.0 and reaction time of 2.9 h. Figure 7 shows that for the temperature range of $10-25^{\circ} \mathrm{C}$ and for the molar ratio of reactants 0.5 to

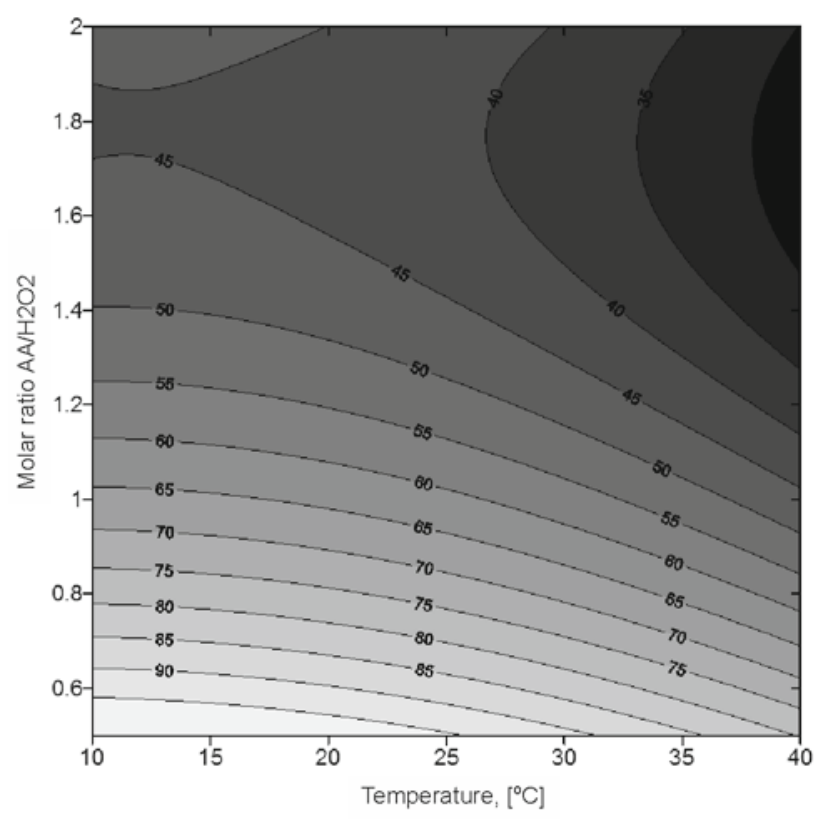

Figure 7. The influence of the technological parameters on the conversion of AA - the dependence of temperature and molar ratio of $\mathrm{AA} /$ hydrogen peroxide (the content of Ti-SBA-15 $2.0 \mathrm{wt} \%$, reaction time $2.9 \mathrm{~h}$ ) 
about 0.6 it is possible to achieve the highest conversion of AA. The raising of the molar ratio of reactants at the lowest temperatures $\left(10-25^{\circ} \mathrm{C}\right)$ causes that the conversion of AA decreases to $40 \mathrm{~mol} \%$. It is possible that the AA molecules take part in stabilization of epoxide compounds, thus do not react with hydrogen peroxide or do not take part in etherification reactions. At higher temperatures for higher molar ratios of reactants also a decrease of the conversion of AA is observed. This phenomenon is connected with the excess of AA in reaction medium.

Figure 8 shows that at temperature range of 10 to about $26^{\circ} \mathrm{C}$ and for catalyst content from 2.0 to $3.6 \mathrm{wt} \%$ it is possible to obtain the highest values the conversion of AA. At the lowest temperatures (to $20^{\circ} \mathrm{C}$ ) the increase the catalyst content above $3.6 \mathrm{wt} \%$ does not cause significant changes in values this investigated function of the process (the decrease to $90 \mathrm{~mol} \%$ ). The increase the temperature in the range of $20-40^{\circ} \mathrm{C}$ for the catalyst content above $3.6 \mathrm{wt} \%$ causes a notable decrease in values of AA conversion to $70 \mathrm{~mol} \%$. Generally, it can be claimed that the lowest temperatures and low catalyst content are the most beneficial to obtain high values of AA conversion.

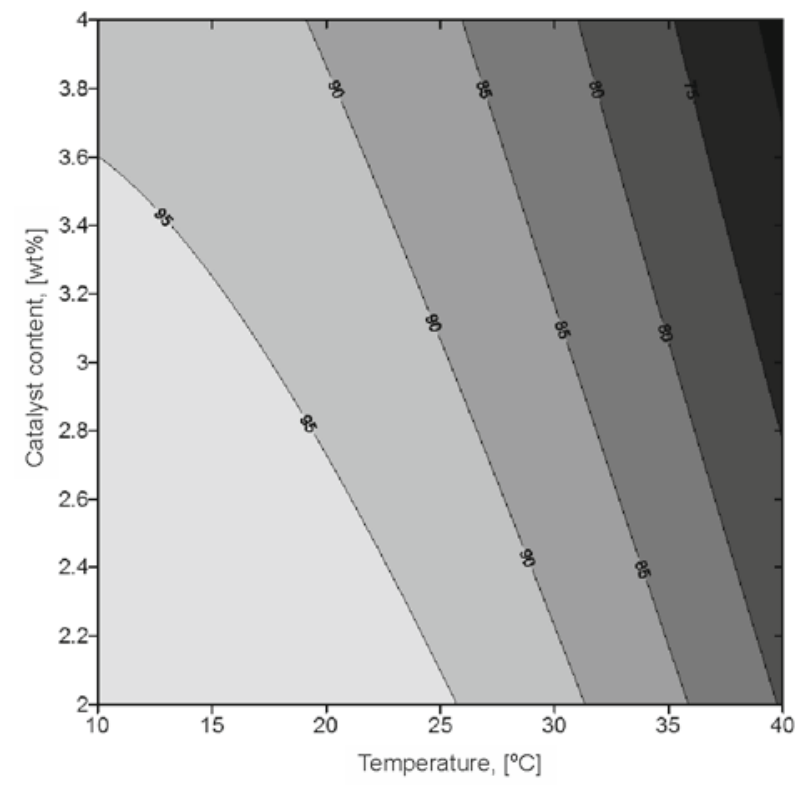

Figure 8. The influence of the technological parameters on the conversion of AA - the dependence of temperature and the content of Ti-SBA- 15 (the molar ratio AA/ hydrogen peroxide 0.5 , reaction time $2.9 \mathrm{~h}$ )

Figure 9 shows that it is the most beneficial to carry out the process at the temperatures from $10^{\circ} \mathrm{C}$ to about $26^{\circ} \mathrm{C}$ and for the reaction time in the range from about 2.35 to $3 \mathrm{~h}$. The reducing the reaction time and increasing the temperature of the process decrease only slightly the conversion of AA. Probably for the longer time the secondary reactions, for example the decomposition of diglycidyl ether, proceed in reaction mixture and the transformations of AA are restricted.

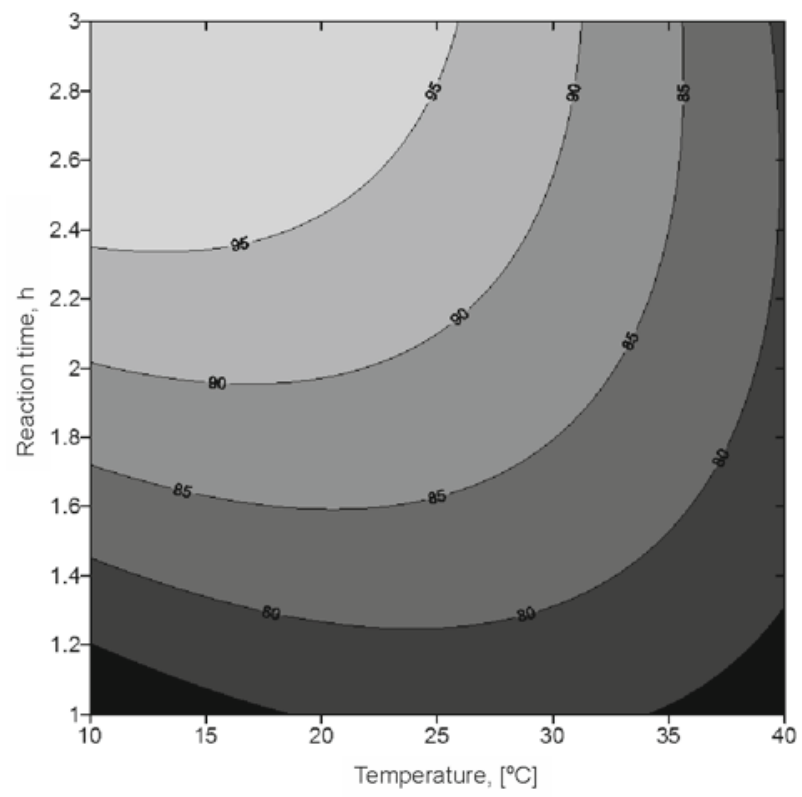

Figure 9. The influence of the technological parameters on the conversion of AA - the dependence of temperature and reaction time (the molar ratio $\mathrm{AA} /$ hydrogen peroxide 0.5 , the content of Ti-SBA-15 $2.0 \mathrm{wt} \%$ )

The selectivity of transformation to organic compounds in relation to hydrogen peroxide consumed $\left(\mathrm{z}_{4}\right)$

The influence of changes of two chosen parameters on the selectivity of transformation to organic compounds in relation to consumed hydrogen peroxide $\left(\mathrm{z}_{4}\right)$ at optimal values of the remaining parameters that allow obtaining the maximum value of the tested function is presented in Figures 10-12.

Figure 10 presents that the highest selectivity of transformation to organic compounds in relation to hydrogen peroxide $(73 \mathrm{~mol} \%)$ can be achieved for the temperature range of $10^{\circ} \mathrm{C}$ to $14^{\circ} \mathrm{C}$ and for the molar ratio of reactants from 0.5 to about 1.0. Probably, at lower temperatures the hydrogen peroxide molecules

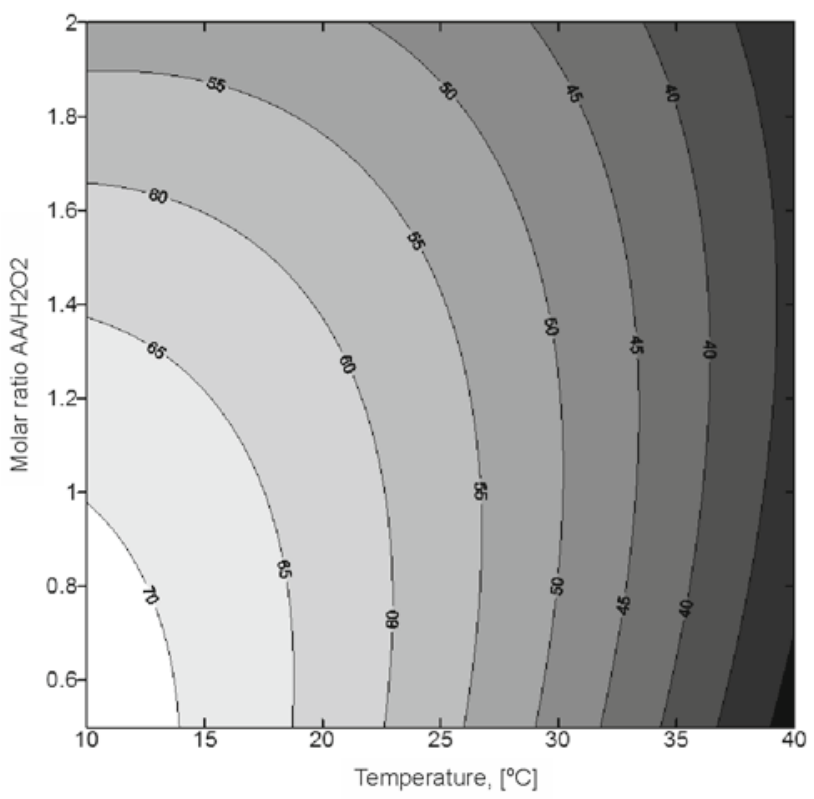

Figure 10. The influence of the technological parameters on the selectivity of transformation to organic compounds in relation to hydrogen peroxide consumed - the dependence of temperature and molar ratio of $\mathrm{AA} /$ hydrogen peroxide (the content of Ti-SBA-15 $2.3 \mathrm{wt} \%$, reaction time $3.0 \mathrm{~h}$ ) 
are more stable and thus are not so susceptible to the decomposition at the active centres of $\mathrm{Ti}$ or under the influence of temperature. The increase of temperature from $25^{\circ} \mathrm{C}$ to $40^{\circ} \mathrm{C}$, practically independent on the molar ratio of AA/hydrogen peroxide, significantly changes the values the investigated function from about $58 \mathrm{~mol} \%$ to about $30 \mathrm{~mol} \%$. On the other hand, the increase of temperature from $10^{\circ} \mathrm{C}$ to $25^{\circ} \mathrm{C}$ has also influence on the selectivity of transformation to organic compounds in relation to hydrogen peroxide consumed (it changes from 73 to $58 \mathrm{~mol} \%$ ) but in this case the molar ratio of reactants has an important influence on the value of the investigated faction (it changes fro $73 \mathrm{~mol} \%$ to about $53 \mathrm{~mol} \%$ ). At low temperatures and for the molar ratio of reactants above 1 the tendency to etherification reaction raised, the hydrogen peroxide molecules have a difficult access to active centres and thus ineffective decomposition of hydrogen peroxide takes place.

Figure 11 shows that at the temperature range of $10-15^{\circ} \mathrm{C}$ and independent on the content of the catalyst, the value $73 \mathrm{~mol} \%$ for the selectivity of transformation to organic compounds in relation to hydrogen peroxide consumed can be reached. The raising of the temperatures from $15^{\circ} \mathrm{C}$ to $40^{\circ} \mathrm{C}$ changes significantly the values of this function from $70 \mathrm{~mol} \%$ to $30 \mathrm{~mol} \%$ - ineffective decomposition of hydrogen peroxide takes place. As shows Figure 11 this phenomenon is independent on the molar ratio of reactants.

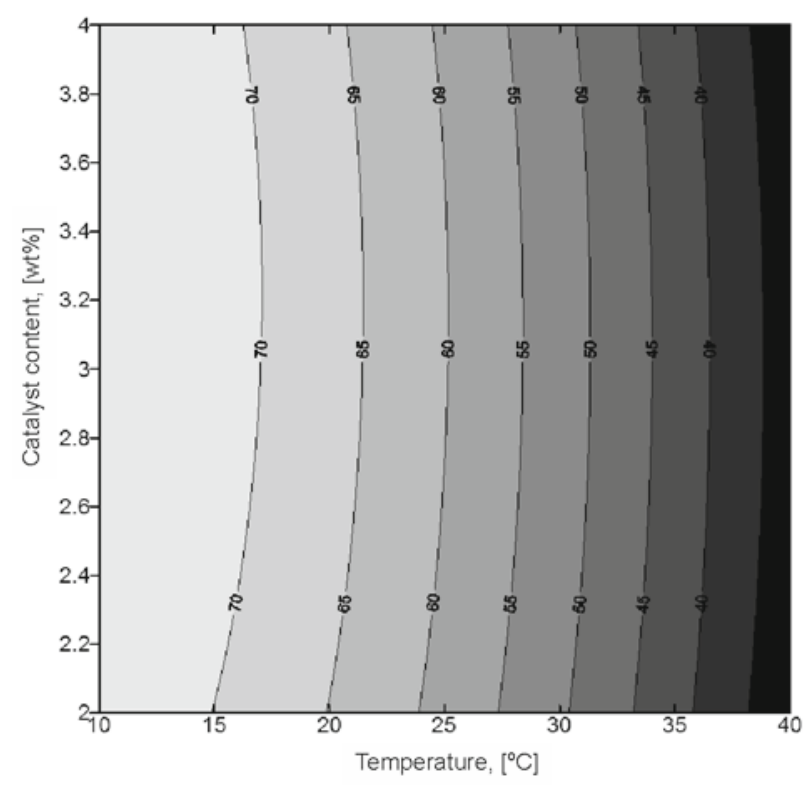

Figure 11. The influence of the technological parameters on the selectivity of transformation to organic compounds in relation to hydrogen peroxide consumed - the dependence of temperature and the content of Ti-SBA-15 (the molar ratio $\mathrm{AA} /$ hydrogen peroxide 0.7 , reaction time $3.0 \mathrm{~h}$ )

Figure 12 shows that in the range of temperatures $10-17^{\circ} \mathrm{C}$ and for the reaction time $2.4-3.0 \mathrm{~h}$ it is possible to obtain the selectivity of transformation to organic compounds in relation to hydrogen peroxide consumed - $73 \mathrm{~mol} \%$. For the reaction time from 1.0 to $1.4 \mathrm{~h}$, the changes of the temperatures from $10^{\circ} \mathrm{C}$ to $40^{\circ} \mathrm{C}$ do not change significantly the value of this function, it amounts to still about $54 \mathrm{~mol} \%$. For longer reaction time (1.4 to $3.0 \mathrm{~h}$ ) the increase the temperature of the reaction cases

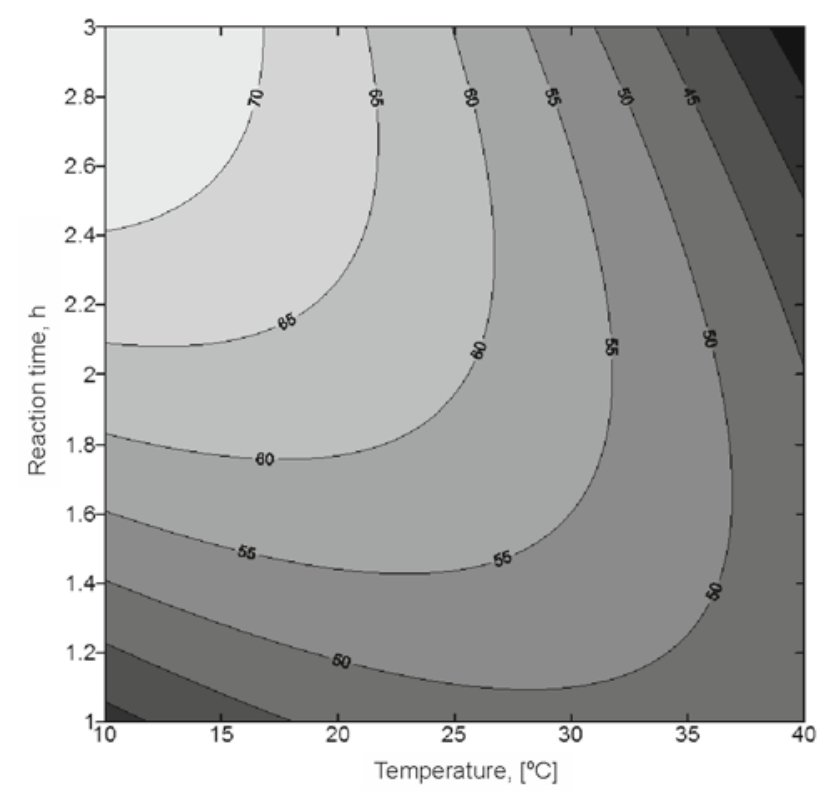

Figure 12. The influence of the technological parameters on the selectivity of transformation to organic compounds in relation to hydrogen peroxide consumed - the dependence of temperature and reaction time (the molar ratio AA/hydrogen peroxide 0.7 , the content of Ti-SBA-15 2.3 $\mathrm{wt} \%)$

significant changes in values the studied function (from $70 \mathrm{~mol} \%$ to about $30 \mathrm{~mol} \%$ ). This decrease is connected with the phenomenon of ineffective decomposition of hydrogen peroxide.

\section{CONCLUSIONS}

The results obtained during the epoxidation of $\mathrm{AA}$ in the direction of glycidol show that at low temperatures $\left(10^{\circ} \mathrm{C}\right)$ it is possible to obtain high selectivity of glycidol, amounting to $54 \mathrm{~mol} \%$. Therefore, aqueous medium is also a suitable environment for the course of the process. At low temperatures, and with a molar excess of allyl alcohol in relation to hydrogen peroxide, the surrounding AA molecules can stabilize glycidol molecules. This prevents hydration and limits the formation of glycerol.

Moreover, the obtained results show that short reaction times are not in favor of the etherification process at ambient temperature or slightly higher temperature. As in the case of other mesoporous titanium silicalite catalysts, the content of the catalyst in the reaction mixture has to be quite high (above $2.9 \mathrm{wt} \%$ ) for the epoxidation and etherification processes to occur.

\section{LITERATURE CITED}

1. Xu, R., Pang, W., Yo, J., Huo, Q. \& Chen, J. (2007). Chemistry of zeolites and related porous materials. Singapore, Republic of Singapore: Wiley.

2. Oyama, T. (2008). Mechanisms in homogeneous and heterogeneous epoxidation catalysis. Amsterdam, Netherlands: Elsevier.

3. Wróblewska, A. \& Fajdek, A. (2010). Epoxidation of allyl alcohol to glycidol over the microporous TS-1 catalyst. J. Hazard. Mater. 35(2), 258-265. DOI: 10.1016/j.jhazmat.2010.02.088.

4. Wróblewska, A. (2012). Optimization of the reaction parameters of epoxidation of allyl alcohol 
with hydrogen peroxide over TS-2 catalysts. Appl. Catal. A: General 309(2), 192-200. DOI: 10.1016/j. apcata.2006.05.004.

5. Wróblewska, A., Fajdek, A. \& Wajzberg, J. (2008). Epoxidation of allyl alcohol to glycidol over titaniumsilicalite Ti-beta and Ti-MCM-41 catalysts. J. $A d v$. Oxid. Technol. 11(3), 468-476.

6. Fajdek, A., Wróblewska, A. \& Milchert, E. (2012). Clean synthesis of 2-methylglycidol over a novel titanosilica catalyst - Ti-MWW under autogenic pressure. Int. J. Chem. Reac. Eng. 10, A10. DOI: 10.1515/1542-6580.2898.

7. Wu, P. \& Tatsumi, T. (2003). Postsynthesis, characterization, and catalytic properties in alkene epoxidation of hydrothermally stable mesoporous Ti-SBA-15. J. Catal. 214, 317-326. DOI: 10.1021/cm010910v.

8. Wróblewska, A. \& Milchert, E. (2009). Liquid phase epoxidation of allylic compounds with hydrogen peroxide at autogenic and atmospheric pressure over mesoporous Ti-MCM-48 catalyst. J. Adv. Oxid. Technol. 12(2), 170-177.

9. Wróblewska, A. \& Makuch, E. (2012). The utilization of Ti-SBA-15 catalyst in the epoxidation of allylic alcohols. Reac. Kinet. Mech. Catal. 105, 451-468. DOI: 10.1007/ s11144-011-0405-1.

10. Wu, P. \& Tatsumi, T. (2002). Postsynthesis, characterization, and catalytic properties in alkene epoxidation of hydrothermally stable mesoporous Ti-SBA-15. Chem. Mater. 14, 1657-1664. DOI: 10.1021/cm010910v.

11. Wittmann, G., Demeester, K., Dombi, A., Dewulf, J. \& Van Langenhove, H. (2005). Preparation, structural characterization and photocatalytic activity of mesoporous Ti-silicates. Appl. Catal.: Environmental 61, 47-57. DOI: 10.1016/j.apcatb.2005.04.010.

12. Berube, F., Kleitz, F. \& Kaliaguine, S. (2009). Surface properties and epoxidation catalytic activity of Ti-SBA-15 prepared by direct synthesis. J. Mater. Sci. 44, 6727-6735. DOI: 10.1007/s10853-009-3566-9.

13. Berube, F., Kleitz, F. \& Kaliaguine, S. (2008). A comprehensive study of titanium-substituted SBA-15 mesoporous materials prepared by direct synthesis. J. Phys. Chem. C 112, 14403-14411. DOI: 10.1021/jp803853m.

14. Milchert, E. \& Wróblewska, A. (1996). Synthesis of Glycidol. Przem. Chem. 75(10), 367-368.

15. Hanson, R. (1991). The synthetic methodology of nonracemic glycidol and related 2,3-epoxy alcohols. Chem. Rev. 91, 437-475.

16. Dworak, A., Trzebicka, B., Wałach, W. \& Baran, K. (1999). Polyglycidol -block-poly(ethylene oxide) - block - polyglycidol: synthesis and swelling properties. Reac. Funct. Polym. 42, 31-36.

17. Toshima, K., Okuno, Y. \& Matsumura, S. (2003). Glycidol - carbohydrate hybrids - a new family of DNA alkylating agents. Bioorg. Med. Chem. Lett. 13(19), 3281-3283. DOI: 10.1016/S0960-894X(03)00659-0.

18. Aragones, S., Bravo, F., Diaz, Y., Matheu, M. \& Catillon, S. (2003). Stereoselective synthesis of $\alpha$-isonucleosides. Terahedron Lett. 44, 3771-3773. DOI: 10.1016/S00404039(03)00743-3.

19. Cassel, S., Debaig, C., Benvegnu, T., Chaimbault, P., Lafosse, M., Plusquellec, D. \& Rollin, P. (2001). Original synthesis of linear branched and cyclic oligo- glycerol standards. Eur. J. Org. Chem. 875-896. DOI: 10.1002/1099-0690(200103).

20. Hauck, F.P. \& Jacobs, G.A. (1981). Anti-arrhythmia agents. US Patent Application No. 4279902. Alexandria: United States Patent and Trademark Office.

21. Rieu, J.P., Patoiseau, J.F., John, G., Legrand, B. \& Verscheure, Y. (2003). Substituted 1-(4-piperydyl)-3-(akrylisothioureas their preparation and their therapeutic application. US Patent Application No. 6531469 B1. Alexandria: United States Patent and Trademark Office.

22. Lukyanenko, G. \& Reder, A.S. (1988). Macroheterocycles. Part 42. A facile synthesis of dihydroxy cryptands and their dehydroxylation J. Chem. Soc., Perkin Trans. 2533-2536.

23. Machleder, W.H., Bollinger, J.M. (1981). Multipurpose hydrocarbon fuel and lubricating oil additive. US Patent Application No. 4259086. Alexandria: United States Patent and Trademark Office.

24. Ermakov, A.S., Bulatov, P.V. \& Tartakovsky, V.A. (1977). The reaction of sulfamic acid derivatives with epoxides. Reaction of sulfamates with diglycidyl and allylglycidyl ether and synthesis of the corresponding aminathes. Rus. Chem. Bull. 46(3), 487-490.

25. Brill, W.F. (1963). The origin of epoxides in the liquid phase oxidation of olefins with molecular oxygen. $J$. Am. Chem. Soc. 85, 141-145.

26. Golowa, B.M., Motowiljak, L.W., Politanskij, S.F., Stjepanow, M.W. \& Czeljadin, W.T. (1974). Opredelenie osnownych komponentow processa poluczenija glicerina putem gidroksilirowanja allilowago spirta. Zavod. Lab. 40, 1192-1195.

27. Montgomery, D.C. (1976). Design and analysis of experiments. New York, USA: Wiley.

28. Nalimowv, W.W. \& Czernowa, V.A. (1967). Statistical methods of experiments planning. Warsaw, Poland: Scientific-Technical Publishers (in Polish).

29. Achnazarova, S.t. \& Kafarov, V.V. (1982). Optimization of experiments in chemistry and chemical technology. Warsaw, Poland: Scientific-Technical Publishers (in Polish).

30. Polański, Z. (1984). Experiments planning in technique. Warsaw, Poland: Scientific-Technical Publishers (in Polish).

31. Polański, Z. \& Górecka-Polańska, R. (1992). Cadex: ESDET 2.2. program, Planning and statistical analysis of experimental investigations applying determined statistical analysis. Cracow, Poland: Department of Technical Development and Implementation (in Polish).

32. Zieliński, R. Statistical tables. (1992). Warsaw, Poland: Scientific Publishers (in Polish).

33. Findeisen, W., Szymanowski, I. \& Wierzbicki, A. (1980). Theory and calculating methods of optimization. Warsaw, Poland: Science Publishers (in Polish). 